\title{
Restoration of wetlands on the Agulhas Plain is unlikely to generate peat
}

AUTHORS:

Anthony Mills ${ }^{1}$

Roland Hunter ${ }^{2}$

\section{AFFILIATIONS:}

'Department of Soil Science, Stellenbosch University, Stellenbosch, South Africa

${ }^{2} \mathrm{C} 4$ EcoSolutions, Cape Town, South Africa

\section{CORRESPONDENCE TO: Anthony Mills}

EMAIL:

mills@sun.ac.za

\section{KEYWORDS:}

carbon; organic soil; South Africa

\section{HOW TO CITE:}

Mills A, Hunter R. Restoration of wetlands on the Agulhas Plain is unlikely to generate peat. S Afr J Sci. 2018;114(1/2), Art \#a0252, 3 pages. http://dx.doi. org/10.17159/sajs.2018/a0252

(c) 2018. The Author(s). Published under a Creative Commons Attribution Licence.
Wetlands in the Nuwejaars Special Management Area (NSMA) on the Agulhas Plain of South Africa are classified as Western Cape Floodplain Wetlands ${ }^{1}$ and are characterised by dense stands of palmiet (Prionium serratum L.f. $)^{2-5}$. Invasions of alien plants and construction of infrastructure are resulting in considerable degradation of ecosystem services emanating from the wetlands. ${ }^{3}$ Large-scale restoration - by removing alien plants and rehydrating soils - is constrained by funding, and consequently new income streams from restored wetland landscapes need to be investigated. One option is to sequester carbon and generate carbon credits during the wetland restoration process. ${ }^{6}$ The economic viability of this option largely depends on the amount of carbon that could be sequestered. Previous studies of Western Cape Floodplain Wetlands ${ }^{1}$ have found that the carbon content of soils in wetlands with palmiet is surprisingly variable (e.g. $\sim 1.3 \%$ in the Kromme River $^{7}$ versus $\sim 24 \%$ in the Goukou River ${ }^{8}$ ). In general, however, wetlands in the Western Cape do not usually have a carbon content of more than $10 \%$, possibly because of the rapid decomposition of organic matter during the hot, dry summer months. ${ }^{9}$

In certain parts of the wetlands of the NSMA there are thick $(>0.5 \mathrm{~m})$ layers of dark soil. The full geographical extent of these layers is not known, partly because they tend to be buried beneath pale sandy sediments (probably deposited by floodwaters) and are only visible at sites where they have been exposed by erosion. Local landowners refer to the dark soil layers as peat. In the South African context, the term peat is generally used in a colloquial manner, with the term organic soils being favoured in the scientific literature. Organic soil layers in South Africa are defined as those with a mean carbon content of at least $10 \%$ throughout a vertical distance of $20 \mathrm{~cm}{ }^{9,10} \mathrm{To}$ our knowledge, the organic carbon content of the dark soil layers in the NSMA, prior to this study, had not been determined; it was consequently unclear whether they could be classified as organic, which would make the term 'peat' colloquially appropriate.

As a first step towards determining the carbon sequestration potential of the NSMA wetlands and resolving whether the dark soil layers were organic, we determined the organic carbon content of distinct soil layers at three sites with different land use histories: (1) D’Alton Farm (34.57233 S, 19.87432 E); (2) Elim Bridge 1 (34.60651 S, 19.79916 E); and (3) Elim Bridge 2 (34.57946 S, $19.75651 \mathrm{E}$ ) (see Figure 1). Site 1 (D'Alton Farm) is located on the bank of the Kastaaings River and has been grazed by domestic livestock for more than 50 years. A dense stand of the alien tree Acacia longifolia was present on the site until 2005, when a severe flood caused extensive damage, removing the trees and exposing the dark soil layers. Given this land use history, we categorised this site as extremely degraded. Site 2 (Elim Bridge 1) is situated in the floodplain of the Nuwejaars River, is relatively undisturbed, and has not been eroded. We categorised this site as non-degraded. Site 3 (Elim Bridge 2) has historically been used as a rangeland for cattle and was cleared of invasive species in 2010 , with a small amount of erosion occurring thereafter. We categorised this site as moderately degraded.

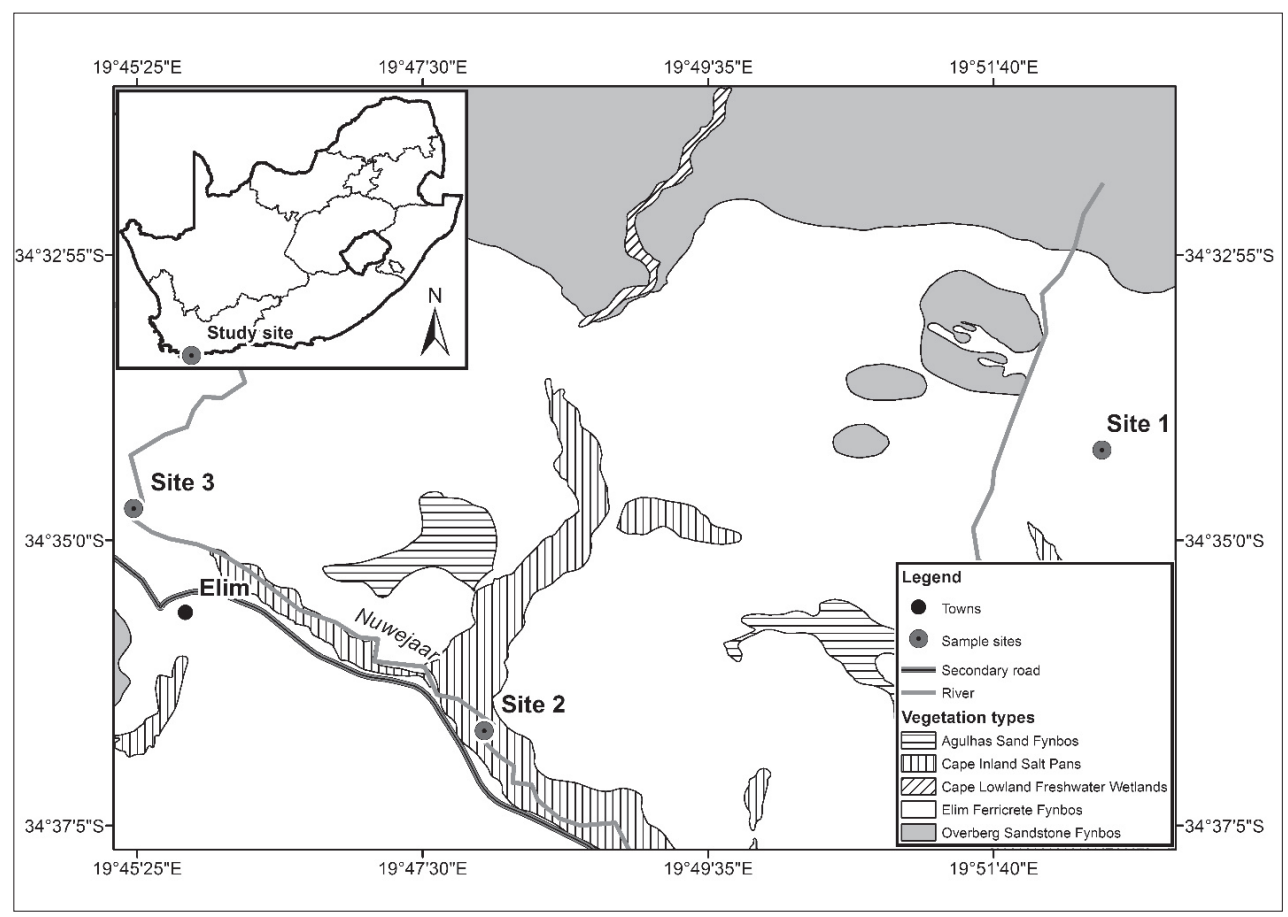

Sources: The map is based on data sets from the Municipal Demarcation Board ${ }^{14}$ and SANB115.

Figure 1: Location of study sites in the Nuwejaars Special Management Area (NSMA), Western Cape, South Africa: Site 1: D’Alton Farm, Site 2: Elim Bridge 1, Site 3: Elim Bridge 2. 
In June 2011, 32 soil profiles were cored with an $8.26-\mathrm{cm}$ auger to a depth of $2.4 \mathrm{~m}$ : 16 soil profiles at Site 1, 8 at Site 2 and 8 at Site 3. Soil samples were taken from each profile at the following approximate depths: $0.1,0.25,0.4,0.8,1.2,1.6,2.0$ and $2.4 \mathrm{~m}$. The samples were subsequently air dried and sieved $(<2 \mathrm{~mm})$. Layers encountered during sampling included: (1) a pale surface layer of quartzitic sand above $0.5 \mathrm{~m}$; (2) dark layers of quartzitic sand with distinct, fine pieces of organic matter; (3) pale layers of quartzitic sandstone gravel below $1 \mathrm{~m}$; and (4) a layer of gleyed clay below $2 \mathrm{~m}$.

To determine whether dark soil layers were relatively enriched in carbon, samples from dark as well as pale layers (except the gleyed clay layer) were analysed for organic carbon using the Walkley-Black method. ${ }^{11}$ Samples of dark soil layers from D'Alton Farm $(n=12)$ and the Elim Bridge $(n=8)$ sites were also analysed for clay, silt, fine sand, medium sand and coarse sand content.

All statistical analyses were conducted in $\mathrm{R}^{12}$ Soil carbon data were analysed for significant differences between site, depth and layer type using mixed-effects models (function Imer; Ime4 package). Layers and depth were separately considered as fixed effects, whereas site and replicate were considered random effects. Data were transformed using BoxCox transformation to reach or improve normality prior to analysis. Post-hoc pairwise comparisons were performed using Tukey's test.

Dark soil layers comprised mainly fine and medium sand, with contents of $57.7 \pm 2.5 \%$ and $21.3 \pm 2.4 \%$ (mean \pm SE), respectively. The contents of other size fractions, namely coarse sand, silt and clay contents were $6.4 \pm 1.0 \%, 6.1 \pm 0.9 \%$ and $8.6 \pm 1.4 \%$, respectively. Site-specific percentages are presented in Table 1. Results of the carbon analyses are presented in Figure 2. No significant differences in carbon content of pale or dark layers between the sites were recorded. The mean carbon content of dark layers $(1.85 \pm 0.1 \%)$ across all sites was significantly greater than that of pale layers $(0.72 \pm 0.1 \% ; p<0.001)$. Shallow (above $0.5 \mathrm{~m}$ ) layers across all sites had a minor but statistically significant greater amount of carbon than deep (below $0.5 \mathrm{~m}$ ) layers $(1.9 \pm 0.1 \%$ versus $1.7 \pm 0.2 \%$ for dark layers; $0.9 \pm 0.2 \%$ versus $0.6 \pm 0.1 \%$ for pale layers; $p<0.001)$.
Table 1: $\quad$ Clay, silt, fine sand, medium sand and coarse sand content (\%) of dark soil layers at three study sites in the Nuwejaars Special Management Area, South Africa. Sample size ( $n)$, means (\%), standard deviation (SD), standard error (SE) and confidence intervals $(\mathrm{Cl})$ are presented.

\begin{tabular}{|c|c|c|c|c|c|c|}
\hline Site & Factor & $n$ & Mean (\%) & SD & SE & Cl \\
\hline \multirow{5}{*}{ D'Alton Farm } & Clay & 12 & 4.0 & 0.5 & 0.1 & 0.3 \\
\hline & Silt & 12 & 3.7 & 3.0 & 0.9 & 1.9 \\
\hline & Fine sand & 12 & 53.4 & 14.1 & 4.1 & 9.0 \\
\hline & Medium sand & 12 & 29.1 & 12.2 & 3.5 & 7.7 \\
\hline & Coarse sand & 12 & 9.8 & 6.4 & 1.9 & 4.1 \\
\hline \multirow{5}{*}{ Elim Bridge 1} & Clay & 8 & 15.3 & 8.0 & 2.8 & 6.7 \\
\hline & Silt & 8 & 11.0 & 3.4 & 1.2 & 2.9 \\
\hline & Fine sand & 8 & 56.1 & 12.2 & 4.3 & 10.2 \\
\hline & Medium sand & 8 & 12.9 & 5.7 & 2.0 & 4.8 \\
\hline & Coarse sand & 8 & 4.7 & 2.0 & 0.7 & 1.7 \\
\hline \multirow{5}{*}{ Elim Bridge 2} & Clay & 8 & 8.8 & 7.8 & 2.7 & 6.5 \\
\hline & Silt & 8 & 4.8 & 3.8 & 1.4 & 3.2 \\
\hline & Fine sand & 8 & 65.8 & 11.1 & 3.9 & 9.3 \\
\hline & Medium sand & 8 & 17.8 & 11.9 & 4.2 & 10.0 \\
\hline & Coarse sand & 8 & 2.8 & 2.9 & 1.0 & 2.4 \\
\hline
\end{tabular}

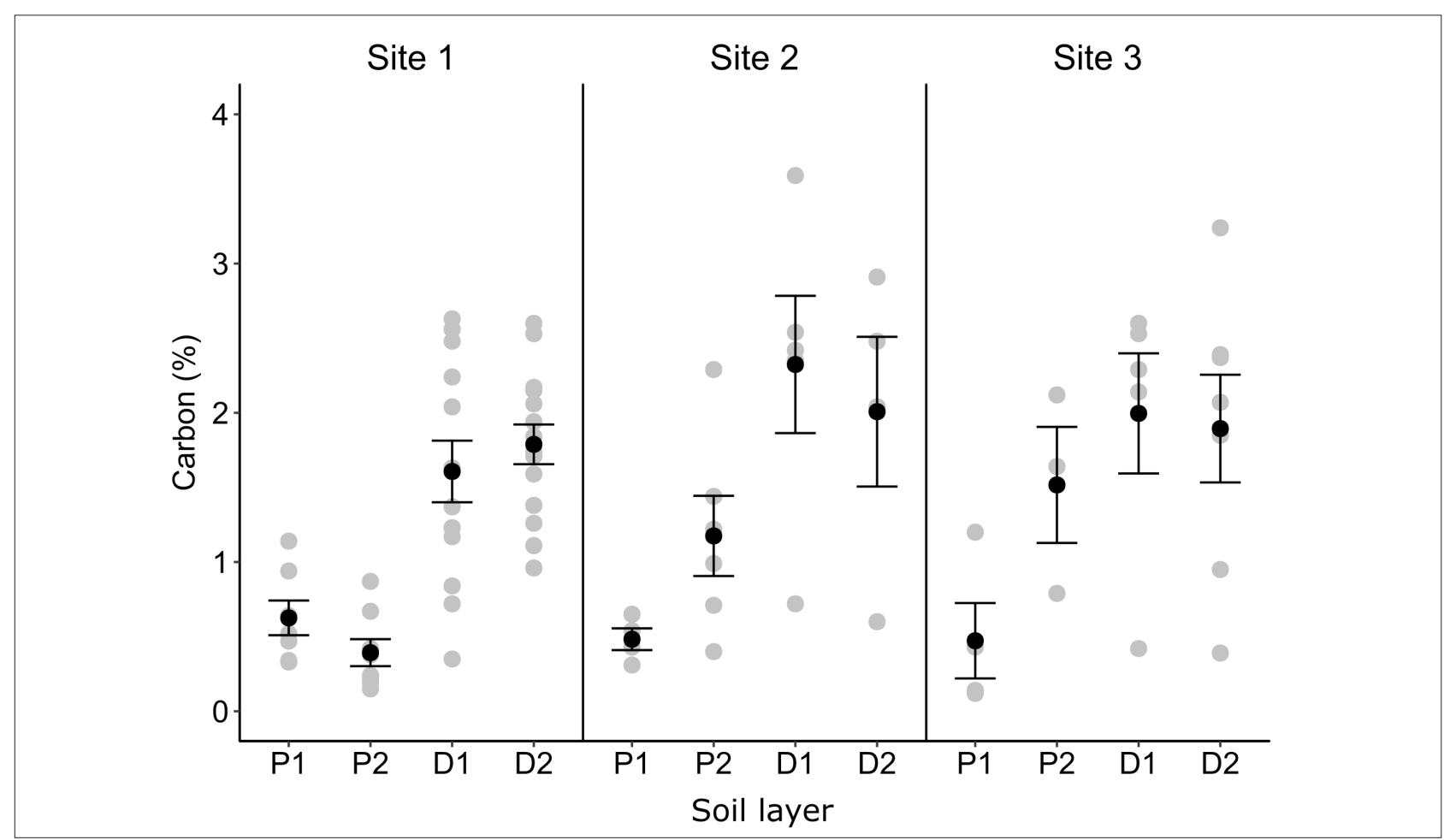

$P 1$, deep pale layers $(n=15) ; P 2$, shallow pale layers $(n=17) ; D 1$, deep dark layers $(n=23) ; D 2$, shallow dark layers $(n=25)$. Individual values are depicted as light grey circles; means and standard errors are depicted as black circles and bars, respectively.

Figure 2: Organic carbon content of shallow $(<0.5 \mathrm{~m})$ and deep $(>0.5 \mathrm{~m})$ pale and dark soil layers at the three study sites in the Nuwejaars Special Management Area, South Africa. 
Methodologies for generating carbon credits in wetlands focus predominantly on peatlands ${ }^{13}$ because restoration of degraded peatlands can be expected to sequester large amounts of carbon per unit area. Our preliminary study at three separate sites in the NSMA did not find any evidence of the presence of degraded peatlands. We expected to find differences in carbon content of the dark soil layers between our study sites because of their different physical conditions in terms of degree of erosion and extent of alien plant invasion. However, no such differences were found, which leads to two preliminary conclusions. Firstly, dark soil layers in undegraded sites in the NSMA are not carbon-rich, given that mean carbon content of these layers was less than $2.5 \%$ across all sites. And secondly, carbon in the dark layers is relatively resilient to decay, given that organic carbon content was similar in sites with markedly different land use histories. Based on our results, opportunities for generating carbon credits through wetland restoration at our three study sites in the NSMA are likely to be limited. A caveat to this conclusion is that our study only investigated a small part of the NSMA. Further research is warranted to determine whether there are organic soils in other parts of the NSMA and to what extent carbon is lost from them after degradation. Until results of such future studies are available, it is probably prudent to avoid the use of the term peat when describing the dark soil layers in these wetlands.

\section{Acknowledgements}

We thank the landowners and management of the Nuwejaars Special Management Area for allowing access to their land, assistance with field sampling, and site-specific information. We gratefully acknowledge the Nuwejaars Wetland Special Management Area, the South African Department of Environmental Affairs, Natural Resources Management Programme and the National Research Foundation (grant number FA2005040700027) for funding this research. Our thanks go in particular to R. Allardice, M. D'Alton and E. Brink. The field work of T. Thabisisani as well as technical support from J. Baum, J. Allen, S. Mochrie and S. Foden are also gratefully acknowledged.

\section{References}

1. Marneweck GC, Grundling PL, Muller JL. Defining and classification of peat wetland eco-regions in South Africa. Pretoria: Department of Agriculture; 2001.

2. Herdien EL, Petersen C, Reed C, Impson D, Belcher A, Ndiitwani T, et al. Ecological state of rivers of the Overberg region 2004/2005. Pretoria: River Eco-status Monitoring Programme; Department of Water Affairs; 2006. Available from: http://www.dwa.gov.za/iwqs/rhp/technical_reports.aspx.
3. South African National Biodiversity Institute. Duiwenhoks and Goukou wetlands prove their worth. The Gumboot. 2007.

4. South African National Biodiversity Institute. Duiwenhoks Goukou. The Gumboot. 2009.

5. Bekker D. The geomorphic origin, evolution and collapse of a peatland dominated by Prionium serratum: A case study of the Tierkloof Wetland, Western Cape [MSc thesis]. Grahamstown: Rhodes University; 2009.

6. Bonn A, Reed M, Evans C, Joosten H, Bain C, Farmer J. Investing in nature: Developing ecosystem service markets for peatland restoration. Ecosyst Serv. 2014;9:54-65. http://dx.doi.org/10.1016/j.ecoser.2014.06.011

7. Ayine N. Plant community distribution and diversity, and threats to vegetation of the Kromme River peat basins [MSc thesis]. Grahamstown: Rhodes University; 2007.

8. Sieben EJJ. Plant functional composition and ecosystem properties: The case of peatlands in South Africa. Plant Ecol. 2012;213:809-820. http:// dx.doi.org/10.1007/s11258-012-0043-3

9. Fey M. Soils of South Africa. Their distribution, properties, classification, genesis, use and environmental significance. Cambridge: Cambridge University Press; 2010.

10. Soil Classification Working Group. Soil classification - A taxonomic system for South Africa. Memoirs on the Agricultural Natural Resources of South Africa no. 15. Pretoria: Department of Agricultural Development; 1991.

11. Walkley A. A critical examination of a rapid method for determination of organic carbon in soils - Effect of variations in digestion conditions and of inorganic soil constituents. Soil Sci. 1947;63:251-257.

12. R Core Team. R: A language and environment for statistical computing. Vienna: R Foundation for Statistical Computing; 2016. Available from: http:// www.R-project.org.

13. Verified Carbon Standard (VCS). Baseline and monitoring methodology for the rewetting of drained peatlands used for peat extraction, forestry or agriculture based on GESTs. Washington DC: VCS; 2011. Available from: https://goo. $\mathrm{gl} / \mathrm{GZFc1u}$

14. Municipal Demarcation Board. 2016 Boundaries, district municipalities. Pretoria: Municipal Demarcation Board; 2016. Available from: http://www. demarcation.org.za/site/shapefiles/

15. South African National Biodiversity Institute. Vegetation map of South Africa, Lesotho and Swaziland [online].c2009 [updated 2012; cited 2017 Dec 07]. Available from: http://bgis.sanbi.org/ 